\title{
How Does Expanding Health Insurance Coverage Affect Workers' Compensation Costs?
}

W

ider health insurance coverage for young Americans under the Affordable Care Act (ACA) reduces their reliance on state workers' compensation programs when they require emergency care, according to RAND research. The RAND analysis of younger workers, which examined millions of medical records in four populous states, shows that the Affordable Care Act may generate widespread and varying impacts on state workers' compensation systems nationwide.

The research indicates that future health care coverage expansions could moderate outlays for workers' compensation insurers. These findings provide new evidence to help guide the thinking of legislators, regulators, insurers, attorneys, and analysts studying workers' compensation policies.

\section{A Natural Experiment}

In the United States, state workers' compensation systems provide around $\$ 30$ billion in medical care for people who are hurt on the job each year. The system is a trade-off: To be eligible to receive workers' compensation, employees must agree not to sue their companies for negligence. The workers' compensation systems are set up and regulated by the states and complement commercial and other health insurance markets.

Despite the volume of care provided under workers' compensation, little is known about how the availability of health insurance affects the frequency and cost of workers' compensation claims. For example, although workers' compensation plans are required to cover on-the-job injuries and illnesses, workers may prefer to avoid the system to prevent conflict with their employers, or they may seek to use workers' compensation to cover injuries and illnesses not incurred at work.

The ACA created the opportunity to test the connections between health insurance coverage and workers' compensation: Under a provision of the ACA implemented in 2010, firms that offer employees health insurance for their dependents are required to let these children stay on their parents' health plans until age 26 .

Thus, a study of workers' compensation claims by people under 26 versus those over 26 might offer insight into how

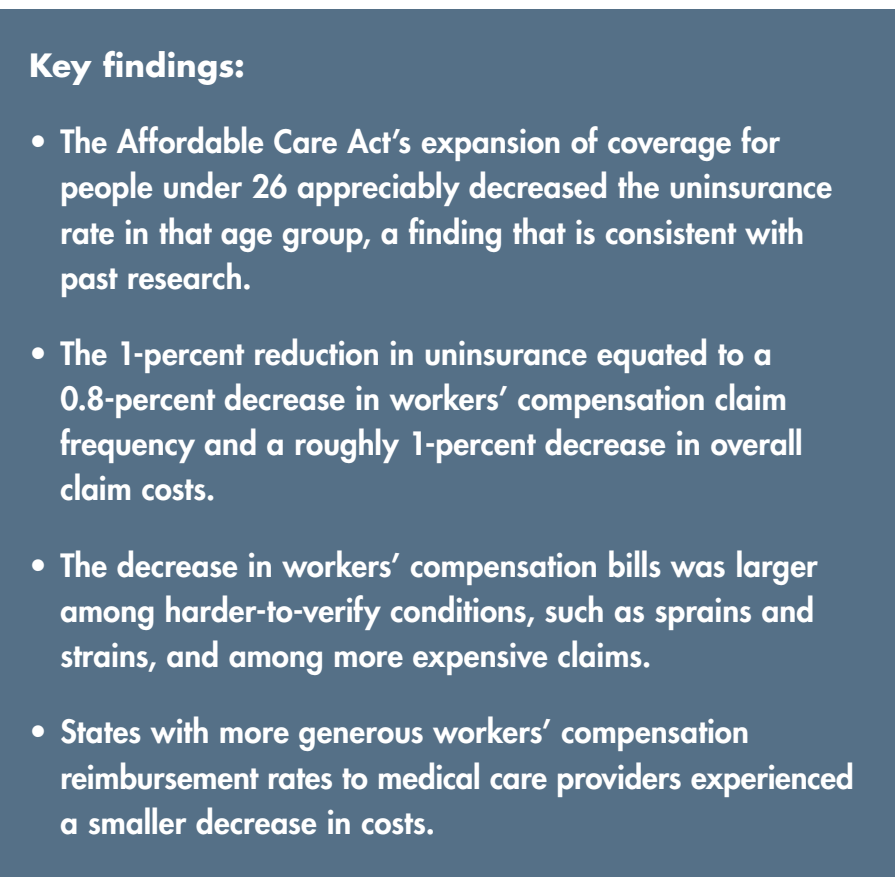

the ACA's ongoing health insurance expansions affect use of workers' compensation (see figure). The groups are similar enough that one would not expect large differences in their respective risks of getting hurt on the job. Given that one group (those under 26) would be eligible for the ACA's dependent care coverage expansion and the other (those over 26) would not, the differences in the two groups' use of workers' compensation may be informative.

\section{Lower or Higher Costs?}

Theoretically, expansion of health insurance access could either lower or raise workers' compensation costs.

For instance, people without health insurance who were injured off the job sometimes claim to have been injured at work to receive subsidized care and coverage. If health insurance access increased, workers compensation costs might drop.

On the other hand, doctors and hospitals might seek to bill care to workers' compensation when it provides more generous reimbursement than other payers, such as private insurance. They also might have an incentive to perform 
How the ACA's Dependent Coverage Expansion Decreased Uninsurance Rates Among Young Adults

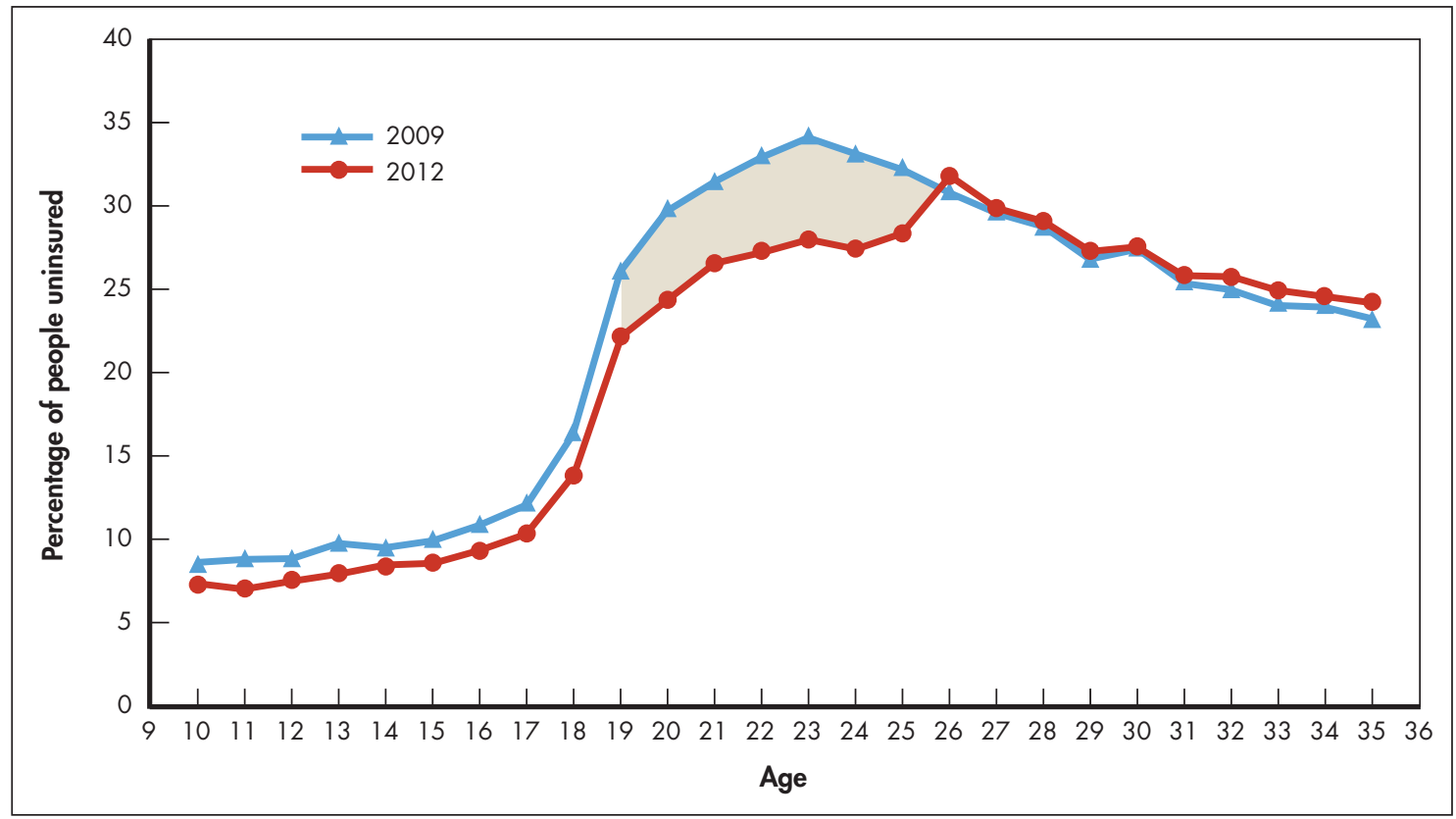

The ACA expanded coverage for people under the age of 26 by making them eligible to stay on their parents' employers' health insurance. That created a sample that the researchers could compare against people just over the age of 26 to explore how health insurance coverage affected use of workers' compensation.

additional procedures on patients covered by workers' compensation if the reimbursement rate is higher.

\section{Deep Data on Workers' Compensation}

The RAND researchers looked at data on more than 17 million hospital visits for young adults in four states: California, Florida, New Jersey, and New York. The date range for the data extended from 2005 through 2012, with some differences in time spans from state to state.

Specifically, the researchers examined state emergency department data, which contain patient discharge records for most emergency department visits. They also looked at state inpatient data, which cover discharge records for inpatient stays that originated in the emergency room. Both data sets were collected by the Agency for Healthcare Research and Quality's Healthcare Cost and Utilization Project. The data provide a complete picture of emergency hospital care in the four states before and after the dependent coverage expansion, including who was billed for that care.

However, the examination excludes some types of medical care that may drive workers' compensation costs, including nonemergency chiropractic care, prescriptions, and psychiatric care. The data used did not include total payments made under workers' compensation. Also, the study looked only at the short-term impacts of health care reform on billings. It did not examine other impacts of reform, such as subsequent worker health or quality of treatment.

Those hospital records were analyzed using a differencein-differences approach wherein the emergency room billings of 23- to 28-year-olds were tracked both before and after the dependent coverage expansion. The experience of the older group (who did not gain health insurance coverage after 2010) provides a useful comparison with the experience of the younger group (who did gain coverage). That analysis allowed a view into whether the number or nature of workers' compensation treatment episodes changed for the under-26 group of patients in 2010 versus the over- 26 group of patients. The two age groups were restricted to 23- to 25-year-olds in the younger group and 26- to 28-year-olds in the older group.

\section{Evidence of Fewer Workers' Compensation Billings}

The analysis showed a statistically significant reduction in workers' compensation billings for the younger group, who gained coverage under the ACA. The magnitude of the reduction was economically significant, with a 1 -percent reduction in uninsurance equating to a 0.8 -percent decrease in workers' compensation claim frequency-and a roughly 1-percent decrease in workers' compensation claim costs. 
That 1-percent cost drop was calculated by taking the 0.8 -percent reduction in claim frequency and scaling it by the amount by which workers' compensation treatments are on average more expensive, which is about one-third. This cost decrease indicates that future health care expansion could reduce workers' compensation outlays.

In 2015, the Congressional Budget Office indicated that when fully implemented, the ACA's coverage expansion is expected to decrease the uninsurance rate for the adult population by about 10 percentage points. Overall, the research found that a 10-percentage-point decrease in uninsurance would be associated with a roughly 8 -percent decrease in the volume of visits billed to workers' compensation. This implies that, at least for the group studied, health insurance and workers' compensation coverage are substitutable for some.

Among other findings, the research indicated that the reductions in claim frequency were driven by harder-to-verify conditions, such as strains and sprains, demonstrating that insurance coverage changes may shift the types of claims presented in workers' compensation systems.

\section{Buttressing the Findings}

Additional lines of analysis bolstered the proposition that expansion of health insurance coverage led to fewer workers' compensation billings:

- The expansion of health care coverage did not affect the total number of emergency hospitalizations for this under-30 population. That finding increases confidence that the results are not likely to reflect bias in selection of which young adults visit the emergency room.

- The research found that Florida workers' compensation billings were impacted much less by the expansion of coverage under the ACA than those in other states. This finding further supports the validity of the analysis, since Florida had a preexisting state requirement expanding coverage to dependents and a much smaller increase in insurance coverage among young adults because of the ACA.

- The timing of the shift in workers' compensation billing strongly favors the ACA coverage expansion as an explanation for fewer billings.

- No measurable differences in workers' compensation billing frequency were found in the researchers' placebo analysis of the pre-ACA period.

\section{The Four States}

Among the states examined, the variety of health insurance requirements and workers' compensation programs provided multiple tests for the researchers' analytical model, along with varied results.

The analysis found that in California, the probability that a particular emergency hospital visit was billed to workers' compensation fell by 0.143 of a percentage point among those in the younger group. Given that 2.8 percent of emergency hospitalizations are billed to workers' compensation, this represents a 5.1-percent reduction in workers' compensation billings for that group (see table).

The overall decline in billings in Florida was not statistically significant, with the state experiencing a smaller change than the other three states examined, but this effect was to be expected, given the dramatically smaller increase in health insurance coverage among those younger than 26. However, there was a small and statistically statistical decline in billings by patients with strains and sprains in the affected group. When scaled by the smaller drop in uninsurance among those under 26 , the effect was proportionally similar to that found in the other states in the analysis.

The reduction in claim frequency in New Jersey among younger workers was smallest among the states (when extrapolated to assume a 10-percent decrease in uninsurance rates among the group). While the reason for the New Jersey result is uncertain, evidence indicates that hospitals in New Jersey receive larger reimbursements under that state's workers' compensation program. One possible explanation is that doctors there more aggressively seek to ensure that work-related injuries are properly attributed to workers' compensation.

\section{For Further Consideration}

The RAND research, which was based on the most comprehensive data and analysis applied to the issue to date, established the effects that expansion of dependent care provisions under the ACA have on workers' compensation billings. It also showed variations in that effect, depending on the types of injuries and the generosity of states' workers' compensation systems.

Whether the decrease in workers' compensation billings observed in this research would be observed in other ACAinduced coverage expansions remains an open question. Some of those expansions will involve different, older populations than the group studied in the four states. Those older workers will possess a different occupational mix and health

Table 1. After the ACA, Reductions in Workers' Compensation Costs

\begin{tabular}{|l|c|c|}
\hline State & $\begin{array}{c}\text { Reduction in Likelihood } \\
\text { That an Emergency Room Visit } \\
\text { Would Be Billed to Workers' } \\
\text { Compensation }\end{array}$ & $\begin{array}{c}\text { Reduction in Workers' } \\
\text { Compensation Cost }\end{array}$ \\
\hline California & $5.1 \%$ & $6.8 \%$ \\
\hline Florida & $0.9 \%$ & $1.2 \%$ \\
\hline New Jersey & $3.7 \%$ & $4.9 \%$ \\
\hline New York & $5.4 \%$ & $7.2 \%$ \\
\hline
\end{tabular}


profile. Also, other types of coverage expansion will shift people into various kinds of insurance beyond the employerprovided systems studied in this research. Thus, care should be taken in generalizing the effects of the ACA's expansion of dependent care to the full suite of ACA reforms.
Still, the research design used in the RAND analysis could be applied more widely — for instance, to data on indemnity payments or nonhospital care. Such studies could provide a more comprehensive portrait of the interplay between health coverage and workers' compensation claim frequency and severity.

This brief describes work done in the RAND Institute for Civil Justice and documented in Health Insurance and Workers' Compensation Claiming: Evidence from the Affordable Care Act, by Philip Armour, Prodyumna Goutam, and Paul Heaton, WR-1153, 2016 (available at www.rand.org/t/WR1153). To view this brief online, visit www.rand.org/t/RB9937. This brief is designed to communicate emerging research to policymakers and the public. Although the working paper on which this brief is based has undergone peer review, the research should be treated as work in progress. Conclusions are preliminary and subject to change. The RAND Corporation is a research organization that develops solutions to public policy challenges to help make communities throughout the world safer and more secure, healthier and more prosperous. RAND is nonprofit, nonpartisan, and committed to the public interest. RAND's publications do not necessarily reflect the opinions of its research clients and sponsors. RAND ${ }^{\circledR}$ is a registered trademark. $\odot$ RAND 2016

Limited Print and Electronic Distribution Rights: This document and trademark(s) contained herein are protected by law. This representation of RAND intellectual property is provided for noncommercial use only. Unauthorized posting of this publication online is prohibited. Permission is given to duplicate this document for personal use only, as long as it is unaltered and complete. Permission is required from RAND to reproduce, or reuse in another form, any of our research documents for commercial use. For information on reprint and linking permissions, please visit www.rand.org/pubs/permissions. 